\title{
О ПРЕДЕЛАХ ПРИМЕНИМОСТИ ДЕМОГРАФИЧЕСКИХ ПРОГНОЗОВ ООН
}

\author{
ЕВГЕНИЙ СОРОКО
}

\begin{abstract}
В 2017 г. был опубликован очередной прогноз мирового населения, сделанный Отделом народонаселения ООН. Согласно этому прогнозу, к 2050 г. численность населения мира составит 9,772 млрд человек, к 2100 г. - 11,184 млрд. В изелом этот прогноз не противоречит ни предыдущими прогнозам ООН, ни прогнозам, выполненным другими организациями. Тем не менее он иногда вызывает и достаточно резкие критические замечания. В данной статье предпринята попытка разобраться в том, что могло послужить причиной критики: новая методика прогнозирования и ее существенная доработка или полученные результаты. С этой ичелью проведен анализ последних прогнозов ООН, методик их составления, использованных данных, результатов прогнозирования, выполненного за последние 15 лет. Обсуждаются недостатки прогнозов ООН, а также ограничения и условность их возможного применения. Показано, что среди возможных причин повыщения в последних прогнозах оценок перспективной численности населения мира к наиболее важным могут быть отнесены: 1) завышение прогнозной младенческой и детской смертности в предыдущих прогнозах; 2) преуменьшение темпов снижения рождаемости в некоторых африканских странах. Предложено обоснование того, что краткосрочные демографические прогнозы должны вызывать доверие и могут быть использованы в практических целях, и отмечена условность применения долгосрочных прогнозов, так как возможные многочисленные непредсказуемые факторы будущего сильно снижают их точность. На уровне отдельных стран большую неопределенность долгосрочного прогноза могут обусловливать крутые повороты в демографической политике или сочиально-политическом устройстве, что иллюстрируется примерами некоторых стран.
\end{abstract}

Ключевые слова: население, страны мира, демографический прогноз, ООН, пересмотр, методика прогнозирования, рождаемость, смертность, долговременный прогноз, вероятностный прогноз.

\section{О КАКИХ ДЕМОГРАФИЧЕСКИХ ПРОГНОЗАХ ИДЕТ РЕЧЬ?}

В данной статье обсуждаются официальные прогнозы мирового населения, которые регулярно публикуются ООН.

- Автор прогнозов. Основное подразделение, отвечающее за их подготовку - Отдел народонаселения (Population Division) Департамента социально-экономических проблем OOH (United Nations Department of Economic and Social Affairs).

- Число прогнозов. ООН производит расчеты с 1951 г. [Wilmoth 2015]. Первые прогнозы выполнялись каждые пять лет, с 1980-х годов они пересматриваются каждые два года [Keilman 1997]. Последний прогноз, опубликованный в 2017 г., - «юбилейный», 25-й в серии этих прогнозов.

ЕВГЕНИЙ ЛЬВОВИч СОРОКо (esoroko@hse.ru), НАЦИОНАЛЬНЫЙ ИССЛЕДОВАТЕЛЬСКИЙ УНИВЕРСИТЕТ «ВЫСШАЯ школА ЭКОНОмики», Россия.

ИССЛЕДОВАНИЕ ВЫПОЛНЕНО В РАМКАХ ПРОГРАММЫ ФУНДАМЕНТАЛЬНЫХ ИССЛЕДОВАНИЙ НИУ ВШЭ В 2017 Г., ПРОЕКТ «ТЕНДЕНЦИИ ДЕМОГРАФИЧЕСКОГО РАЗВИТИЯ В РОССИИ В 2005-2015 ГГ. В КОНТЕКСТЕ ДОЛГОВРЕМЕННЫХ ДЕМОГРАФИЧЕСКИХ ТРЕНДОВ».

СТАТЬЯ ПОСТУПИЛА В РЕДАКЦИЮ В МАРТЕ 2018 Г. 
- Название прогнозов. Основные, регулярно рассчитываемые прогнозы ООН носят название World Population Prospects (Перспективы мирового населения), а их очередная версия называется «пересмотром» (revision) с указанием года.

- Горизонт прогнозирования. Первые прогнозы были сделаны на предстоящий период в 20-30 лет, например, в 1975 г. - до 2000 г. В начале XXI века прогнозы стали выполняться до середины века, а последние пересмотры делаются уже до 2100 г. Кроме того, несколько раз делались сверхдолгосрочные прогнозы, например, в 1998 г. - до 2150 г., а в 2004 г. - до 2300 г. Они назывались, в отличие от регулярных пересмотров «перспектив», именно прогнозами: World Population Projections to 2150 [WPP 1998] или просто World population to 2300 [WP 2004].

- Страны и регионы. Первоначальные прогнозы делались для мира в целом и крупных регионов. С 1968 г. ООН делает прогнозы народонаселения для отдельных стран мира. В пересмотре 2017 г. число стран и макрорегионов составляет 241. В перечень стран включены все страны с численностью населения не менее 90 тыс. человек [WPP 2015b: 1]. Эта предельная величина неоднократно снижалась, в конце XX века она составляла 150 тыс. [KeiIman 1997].

- Методика прогнозирования постоянно совершенствуется. Некоторые первые вехи в истории прогнозов народонаселения были отмечены в работе Кельмана [Keilman 1997]. В 1958 г. впервые прогнозы были основаны на концепции демографического перехода и теории стабильного населения. В прогнозах 1960 и 1965 гг. были использованы методы непрямого оценивания демографических показателей для стран и регионов с неполной информацией о населении. С 1965 г. прогнозы рассчитывались с использованием компьютеров, что позволило использовать модельные профили рождаемости, смертности и миграции. Существенному углублению понимания демографических процессов способствовали обследования World Fertility Survey, проведенные в 1974-1982 гг. Улучшения в методике имели постепенный характер и обеспечили повышение точности прогнозов. За 65-летнюю историю очень трудно выделить какие-либо два-три существенных и наиболее важных изменения в этой методике ввиду их многочисленности и широкого спектра различных аспектов прогнозирования: используемых статистических данных, демографических теорий, математических моделей, сценариев будущего, технологии обработки. По этой причине предлагается говорить об общей «эволюции» методики прогнозирования. В данной статье не представляется возможным дать детальное описание всей истории этих прогнозов, но их современная методология будет в основных чертах описана.

- Число вариантов прогноза. В первых прогнозах ООН были использованы три основных, ставших в демографии уже традиционными, сценария предстоящей динамики показателей: средний, высокий и низкий. В пересмотре 2004 г. было представлено пять вариантов. В последнем прогнозе 2017 г. предложено уже девять таких сценариев: средний, высокий и низкий варианты, сценарий неизменной рождаемости, варианты текущего замещения поколений, нулевой миграции, неизменной смертности, инерционный сценарий (замещающая рождаемость, неизменная смертность, нулевая миграция), а также вариант неизменной смертности и рождаемости. 
- Публикаиия результатов прогноза. Первые пересмотры прогнозов ООН были доступны в виде 600-800-страничных томов формата энциклопедии, которые рассылались на средства ООН в научные учреждения и библиотеки. В настоящее время прогноз представлен на интернет-сайте прогноза WPP [WPP 2017]. Размещенные на нем сотни файлов таблиц, графиков и десятки других документов уже трудно представить себе полностью напечатанными на бумаге.

\section{ЧТО НОВОГО В ПОСЛЕДНИХ ПРОГНОЗАХ ООН?}

Каждый очередной пересмотр содержит ряд обновлений, отличающих его от предыдущих. С одной стороны, это новейшая информация по отдельным странам, которая появляется в результате проведения переписей населения, специальных обследований здоровья и репродуктивных планов, с другой - постоянно совершенствующаяся методика прогнозирования, стремящаяся разработать новые сценарии демографической перспективы, расширить горизонт прогнозирования, учесть последние достижения современной науки. Последние четыре прогноза (пересмотров 2010, 2012, 2015, 2017 гг.) используют методику вероятностного демографического прогнозирования.

\section{ЧТО ПОСЛУЖИЛО ПРИЧИНОЙ РОСТА ИНТЕРЕСА К ПРОГНОЗАМ ООН?}

Публикация результатов сделанных ООН прогнозов мирового населения вызывает большой интерес. Особенно заметно выросло внимание к четырем прогнозам последних пересмотров: 2010, 2012, 2015 и 2017 г. (рисунок 1).

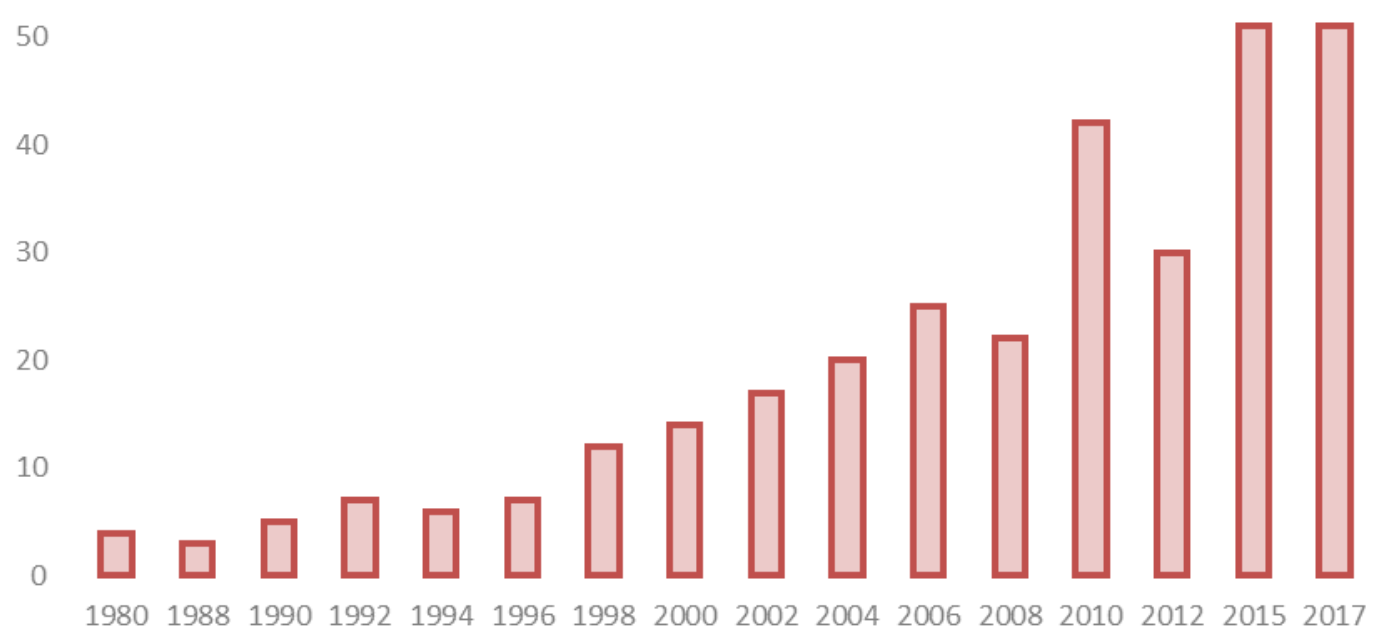

Рисунок 1. Число ссылок на World Population Prospects по годам пересмотра

Примечание. Представлены 316 ссылок, содержашихся в 193 статьях и сайтах, найденных 28.04.2018 в первых 200 результатах Яндекс- и Google-поиска по фразе «World population prospects revision».

Дело не столько в количественных оценках, сколько в качественно новой перспективе населения мира. Те прогнозные оценки населения, которые считались давно уже принятыми специалистами и широкой общественностью, были подвергнуты сомнению 
и потребовали переосмысления. Несомненно, одной из причин переоценки стало серьезное усовершенствование методики, переход к использованию вероятностного прогнозирования. Подробно эта методика описана в журнале Science [Gerland et al. 2014]. Ее нельзя считать абсолютно новой, еще более 15 лет назад она была применена к оценкам перспектив мирового населения [Lutz et. al 1997]. Поэтому основная причина роста интереса к прогнозу ООН - именно результаты прогнозирования, принципиально отличающиеся как от прогнозов Лутца, Сандерсона, Щербова [Lutz et. al 1997], так и от предыдущих прогнозов ООН, сделанных в начале века. Суть отличий можно кратко сформулировать так: по предыдущим прогнозам мирового населения с большой вероятностью его численность стабилизируется еще до конца XXI века и начнется его некоторое сокращение. По новым же прогнозам ООН наиболее вероятным является продолжение роста мирового населения в течение всего XXI века вплоть до 2100 г. Такое существенное расхождение вызвало не только бум интереса в мировой прессе, но и состояние шока, если не паники, у некоторых политиков и специалистов. Вот некоторые заголовки статей в мировой прессе:

- «Economist» - «Исследования ООН разжигают страхи демографического взрыва. Без паники: тревоги неоправданны» [Population projections... 2014];

- «National Geographic» - «11 миллиардов человек на Земле? Новые прогнозы народонаселения разбивают вдребезги предыдущие оценки» [Kunzig 2014];

- «Science» - «Стабилизация мирового населения маловероятна в текущем столетии» [Gerland et al. 2014];

- «Forbes» - «Спорные предположения в прогнозе ООН в 9,8 млрд» [Worstall 2017].

- Появились и критические высказывания в адрес последних прогнозов ООН, в том числе достаточно резкие. В качестве примера можно привести статью Николаса Эберштадта в “The Wall Street Journal”, озаглавленную «Новый взрыв народонаселения запросто может оказаться "липой“»»

Важно отметить, что для широкой публики, действительно, некоторые изменения в прогнозах ООН от пересмотра к пересмотру могут показаться неожиданными и непонятными, тем более что ряд изданий искусственно подогревают интерес своими заголовками с использованием методов, чаще применяемых желтой прессой. Что же касается демографов и специалистов, которые регулярно используют прогнозы в своей работе, то для них эти результаты не воспринимаются как совершенно неожиданные или принципиально новые. Они лишь несколько сдвигают количественные оценки нашего текущего понимания будущего. Резкий характер высказываний некоторых специалистов (например, Эберштадта ${ }^{2}$ ) объясняется, главным образом, расхождением их концептуальных взглядов с мнением экспертов ООН на то, можно ли предсказывать демографическое будущее и как это делать.

\footnotetext{
${ }^{1}$ Eberstadt N. (2014). The new population boom could easily be a dud // The Wall Street Journal. 22 (Sept.) (дата обращения: 25.09.2017).

2 Там же. 
Рассмотрим основные положения методики прогнозирования для понимания возможных причин эволюции результатов прогнозов ООН от пересмотра к пересмотру.

\section{МЕТОДОЛОГИЯ ПРОГНОЗА ООН ПЕРЕСМОТРА 2015 Г .}

1. Исходные данные о населении. Каждый новый пересмотр использует наиболее свежие данные демографической статистики стран мира из всех доступных источников, включая переписи населения, обследования здоровья и репродуктивного поведения, регистры населения, статистику естественного движения населения, а также любые другие источники, например сведения о беженцах. При появлении новых данных любые предыдущие оценки демографических показателей в базовом периоде 19502015 гг. могут быть обновлены и ретроспективно пересчитаны. В пересмотре 2015 г. использованы результаты более 1600 переписей населения [WPP 2015b: 3].

2. Наибольшая сложность такой оценки показателей возникает для тех стран, где демографическая статистика имеет различные изъяны: переписи населения не проводятся вообще или происходят нерегулярно, качество учета низкое из-за значительного недоучета событий, неточностей регистрации возраста или отсутствия учета вообще. Например, достоверные сведения о детской смертности для периода 2010-2015 гг. имеются по 165 странам (92\% мирового населения) [WPP 2015b: 4]. Для стран с указанными проблемами на уровне каждой конкретной страны Отдел народонаселения использует различные методы непрямого оценивания, результаты выборочных демографических обследований, краткосрочного прогнозирования, а также другие методы.

3. Ситуация с регистрацией смертности взрослого населения также оставляет желать лучшего: лишь 53,7\% населения мира проживает в 101 стране, где после 2010 г. имеется удовлетворительная по качеству статистика смертности [WPP 2015b: 5]. Для остальных стран с отсутствием данных или устаревшей информацией также используются непрямые методы оценивания и модельные таблицы смертности.

4. При прогнозировании структуры населения и демографических событий используется так называемый когортно-компонентный метод, позволяющий делать расчеты демографического баланса для каждой страны на горизонте прогнозирования с использованием основных составляющих динамики населения: рождаемости, смертности и международной миграции. Ввиду различного качества данных о населении для каждой страны должны быть найдены и использованы наиболее свежие и точные сведения, модели или косвенные оценки. В этом случае наиболее существенным требованием является необходимость обеспечить совместимость различных данных из разных источников [WPP 2015b: 7].

5. Еще один важный дополнительный этап подготовки прогноза населения, выполняемый Отделом народонаселения, - анализ и обеспечение совместимости показателей и трендов между странами [WPP 2015b: 13]. Например, может потребоваться разбор случаев «выбросов» показателей в некоторых странах на фоне соседних или в сравнении со значениями в макрорегионе, а для международной миграции необходимо обеспечить ее баланс на нулевом уровне для мира в целом. 
6. Прогноз рождаемости производится отдельно для трех групп стран: с высоким уровнем рождаемости, где еще не началось ее снижение или это снижение только начинается; со средним уровнем рождаемости не ниже 2,1 ребенка на 1 женщину в 2010 г.; с низким уровнем рождаемости менее 2,1 [WPP 2015b: 15]. Прогнозирование базируется на положениях теории демографического перехода с классификацией состояния каждой страны на одной из трех ключевых стадий перехода: фаза 1 - высокой рождаемости; фаза 2 - снижения рождаемости, для которой переход к новому низкому уровню описывается двойной логистической функцией с использованием байесовской иерархической модели; постпереходная «восстановительная» фаза 3, для которой прогнозирование выполняется с использованием авторегрессионных моделей для временных рядов [WPP 2015b: 17].

7. На следующем этапе для каждой страны производится стохастическая имитация с использованием метода МСМС (Монте-Карло Марковские цепи) [Sevcikova et al. 2013: 5]. Например, для рождаемости производится имитация 600 тыс. траекторий будущей динамики. Основное преимущество, которое достигается стохастической имитацией, состоит в том, что наряду со средним значением демографических показателей появляется возможность рассчитать доверительные интервалы для каждого из них. В размещаемых результатах прогноза приводятся два основных варианта доверительных интервалов: 80 и 95\%.

8. Для каждой страны также производится построение будущих траекторий для ожидаемой продолжительности жизни мужчин и женщин с учетом изменений возрастных профилей смертности, основанное на использовании системы стохастического прогнозирования, аналогичного применяемому при прогнозе рождаемости.

9. Особенностью последних прогнозов ООН является не только внедрение усовершенствованных методов, моделей и алгоритмов расчетов, но и разработка пакетов прикладных компьютерных программ, позволяющих реализовать их участникам коллектива, который эти прогнозы готовит. Такие пакеты дают возможность увидеть, оценить, протестировать каждый этап расчетов, выявить специфику отдельных стран и точность настройки модельных параметров, увидеть особенности отдельных регионов и стран на графиках и картах. Отметим, что эти пакеты распространяются не только среди непосредственных участников авторского коллектива очередного пересмотра, но могут быть использованы и другими демографами в их прогнозных расчетах.

10. Перечислим вкратце некоторые другие этапы подготовки результатов прогноза: интерполяция и агрегирование показателей по возрасту, полу, периоду, странам, ранжирование стран по значению отдельных демографических показателей, оформление ключевых показателей в виде таблиц и графиков, описание результатов прогноза, их анализ и представление в сравнении с предыдущими прогнозами, размещение файлов с результатами прогнозных показателей и других документов на сайте UN DESA PD [WPP 2017] и др. 


\section{МОЖНО ЛИ ДЕМОГРАФИЧЕСКИЙ ПРОГНОЗ ООН ДАЖЕ ОТДЕЛЬНО ВЗЯТОГО ПЕРЕСМОТРА РАССМАТРИВАТЬ КАК «МНЕНИЕ ЭКСПЕРТОВ»?}

Столь легковесная оценка совершенно непригодна применительно к прогнозам $\mathrm{OOH}$, поскольку даже краткое описание методов прогнозирования достаточно ясно показывает, что прогноз представляет собой результат сложной организационно-технической процедуры, включающей многомерные информационные массивы и персонал, математические модели и алгоритмы расчетов, компьютерные программы и интернетсайты с документацией, публикации и презентации. Для прогноза пересмотра 2015 г. можно дать некоторые ключевые количественные оценки объема и сложности выполненных работ: результаты прогнозных расчетов размещены в $\sim 60$ млн графоклеток в более чем сотне многомерных таблиц в пространстве периода в 150 лет (65 лет или более - базовый период, 85 лет - прогнозный), результаты представляют более двухсот территориальных единиц - стран и регионов мира, пола, возраста, прогнозных сценариев, демографических процессов (рождаемости, смертности, миграции), а также сотни тысяч вариантов статистических испытаний. Минимальная оценка общего объема вычислений, сделанных при построении прогноза, $\sim 3^{*} 10^{14}$.

\section{КАК ВЫГЛЯДИТ КЛЮЧЕВОЙ РЕЗУЛЬТАТ ПРОГНОЗА?}

Историческая динамика и перспективы численности населения мира по прогнозу последнего пересмотра представлены на рисунке 2. 


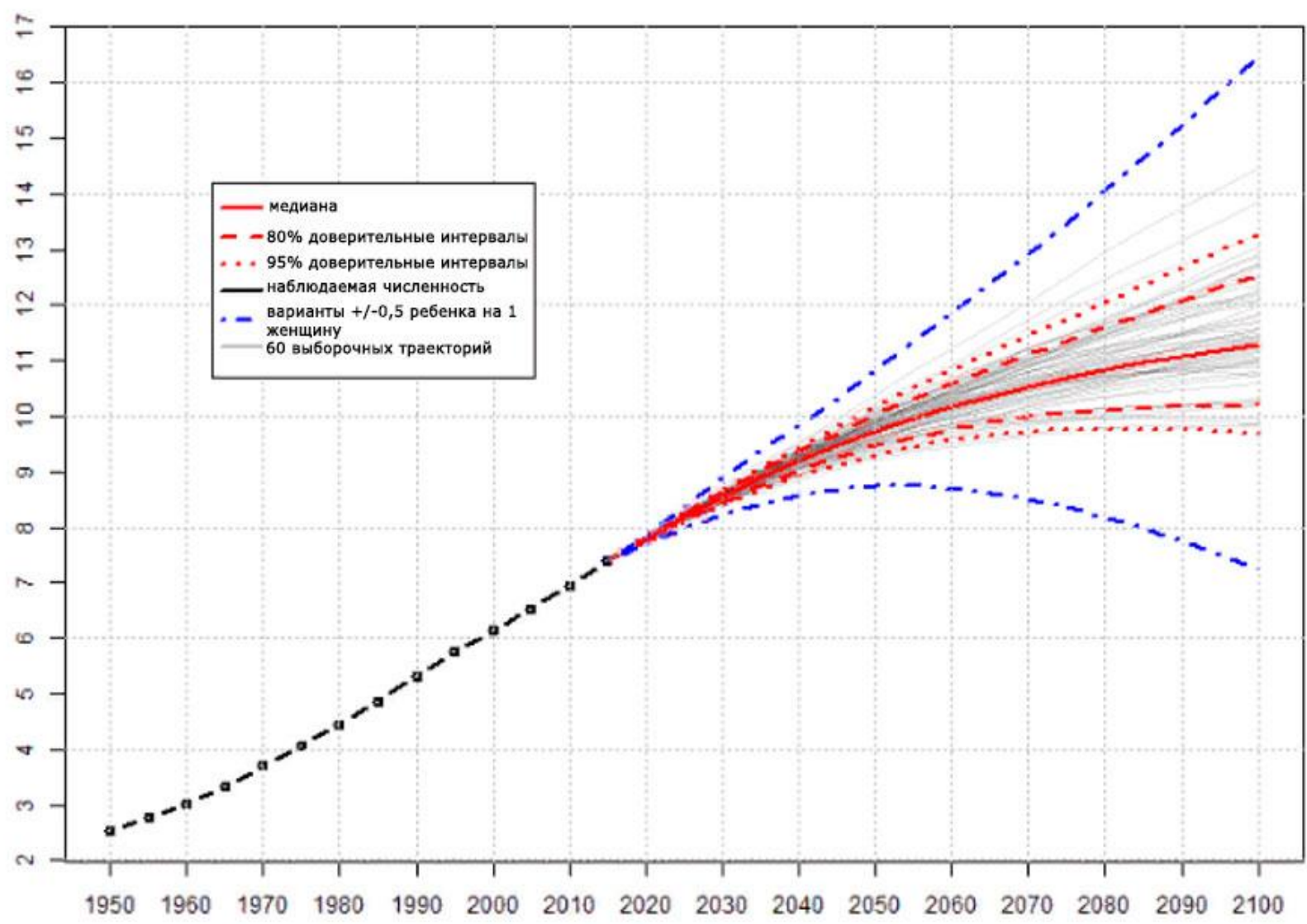

Рисунок 2. Наблюдаемая и прогнозная численность населения мира до 2100 г. по прогнозу пересмотра 2017 г. млрд человек

Источник: [WPP 2017].

Мировое население к 2017 г. составляло 7,6 млрд человек (50,4\% -мужчины и 49,6\% - женщины). Оно увеличилось на 1 млрд с 2005 г. и на 2 млрд с 1993 г. В 2017 г. число детей до 5 лет составило 9\%, до 15 лет - 26\%, пожилых в возрасте 60 лет и старше - 13\%, и 80+ лет $-2 \%$. Ежегодный прирост численности населения Земли в настоящее время оценивается в 83 млн человек. По среднему варианту прогноза к 2030 г., несмотря на снижение рождаемости, мировое население достигнет 8,6 млрд, к 2050 г. - 9,8 млрд, а к 2100 г. - 11,2 млрд человек. Даже если предположить, что снижение рождаемости ускорится, рост численности населения будет продолжаться как минимум до 2050 г. К 2030 г. мировое население с вероятностью 95\% составит от 8,4 до 8,7 млрд человек. Этот прогноз к 2050 г. дает величину от 9,4 до 10,2 млрд, а к 2100 г. - от 9,6 до 13,2 млрд человек [WPP 2015a: Кеу finding and advance tables: 12].

\section{КАКОВА ЭВОЛЮЦИЯ ПЕРСПЕКТИВ МИРОВОГО НАСЕЛЕНИЯ ООН?}

Представленные ключевые цифры из пересмотра 2017 г. отличаются от того, что содержали предыдущие пересмотры. Общая тенденция прогнозных оценок мирового населения - рост от пересмотра к пересмотру. Например, прогноз численности мирового населения к 2050 г. по пересмотру 2002 г. составил 8,9 млрд человек, 2010 г. - 9,3 млрд, а по пересмотру 2017 г. - уже почти 9,8 млрд. Прогноз же на 2100 г. составил по пересмотру 2010 г. 10,1 млрд, а 
2015 и 2017 г. - уже 11,2 млрд человек. Более детально прогноз по семи последним пересмотрам представлен в таблице 1.

Таблица 1. Прогнозная численность мирового населения в 2050 и 2100 г. по среднему варианту прогнозов ООН пересмотров 2004-2017 гг., млрд человек

\begin{tabular}{c|c|c|c|c|c|c|c}
\hline Горизонт & \multicolumn{7}{|c}{ Год пересмотра } \\
\cline { 2 - 8 } прогноза & 2004 & 2006 & 2008 & 2010 & 2012 & 2015 & 2017 \\
\hline 2050 г. & 9,08 & 9,19 & 9,15 & 9,30 & 9,55 & 9,73 & 9,77 \\
2100 г. & - & - & - & 10,13 & 10,85 & 11,21 & 11,18 \\
\hline
\end{tabular}

Источники: [WPР 2004, 2006, 2008, 2010, 2012, 2015a, 2017].

\section{В ЧЕМ ПРИЧИНА ИЗМЕНЕНИЙ В ПРОГНОЗАХ?}

Ответ на этот вопрос, по-видимому, не может быть однозначным. Рассмотрим несколько возможных причин роста оценок.

Причина №1. Оценки и прогнозные значения младенческой и детской смертности, использованные при построении прогнозов предыдущих пересмотров, оказались сильно завышенными, можно сказать излишне алармистскими. Реальная картина по мере ее уточнения и появления более свежих и точных данных достаточно быстро показала их ошибочность и, естественно, потребовала уточнения в следующих пересмотрах. В качестве примера приведем лишь одну страну - Мали, где по прогнозу пересмотра 2006 г. детская смертность в 2000-2005 гг. оценивалась на уровне 219 на 1000 родившихся живыми, прогноз уровня детской смертности на 2010-2015 гг. составил 180,5, а на 2045-2050 гг. 87,2. В прогнозе же пересмотра 2017 г. оценка на 2010-2015 гг. была существенно меньшей - 125 на 1000, а прогноз на 2045-2050 гг. был изменен до величины 27,3 на 1000. В качестве иллюстрации в таблице 2 данный показатель представлен подробнее для трех стран с высоким сегодняшним уровнем детской смертности.

Таблица 2. Смертность детей до 5 лет, оценка и средний вариант прогноза ООН по данным пересмотров 2006 и 2017 г., на 1000 родившихся живыми, Афганистан, Ангола и Мали

\begin{tabular}{l|ccc|c|c}
\hline \multirow{2}{*}{ Страна } & \multicolumn{3}{|c|}{ Пересмотр 2006 г. } & \multicolumn{2}{c}{ Пересмотр 2017 г. } \\
\cline { 2 - 6 } & $\begin{array}{c}2000-2005 \\
\text { (оценка) }\end{array}$ & $\begin{array}{c}2010-2015 \\
\text { (прогно3) }\end{array}$ & $\begin{array}{c}2045-2050 \\
\text { (прогно3) }\end{array}$ & $\begin{array}{c}2010-2015 \\
\text { (оценка) }\end{array}$ & $\begin{array}{c}2045-2050 \\
\text { (прогно3) }\end{array}$ \\
\hline Афганистан & 252,0 & 219,9 & 106,9 & 81,3 & 30,8 \\
Ангола & 245,9 & 213,1 & 102,1 & 101,1 & 49,3 \\
Мали & 219,0 & 180,5 & 87,2 & 125,1 & 42,8 \\
\hline
\end{tabular}

Источник: [WPP 2006, 2017].

\section{ЧТО ПРОИСХОДИТ С РОЖДАЕМОСТЬЮ?}

С оценками и прогнозами рождаемости дела обстоят по ряду стран несколько хуже, и это возможная Причина №2. По данным ООН рождаемость действительно продолжает снижаться в странах, где ее уровень остается еще высоким, однако темпами значительно более низкими, чем считалось ранее. Это явление даже получило свое название «stall» 
(застой). Так, в Нигерии по прогнозу пересмотра 2006 г. коэффициент суммарной рождаемости (КСР) в 2000-2005 гг. оценивался на уровне 5,85 ребенка на 1 женщину, прогноз на 2010-2015 гг. составил 4,74, а на 2045-2050 гг. - 2,4. В прогнозе же пересмотра 2017 г. оценка на 2010-2015 гг. оказалась значительно более высокой $-5,74$, а прогноз на 2045-2050 гг. - 3,55. В результате прогнозы для Африки предсказывают четырехкратный рост ее населения к концу XXI века. Перспектива изменений рождаемости на примере трех африканских стран с высоким уровнем рождаемости представлена в таблице 3.

Таблица 3. Коэффициент суммарной рождаемости, оценка и средний вариант прогноза ООН пересмотров 2006 и 2017 г., детей на 1 женщину

\begin{tabular}{l|c|c|c|c|c}
\hline \multirow{2}{*}{ Страна } & \multicolumn{3}{|c|}{ Пересмотр 2006 г. } & \multicolumn{2}{c}{ Пересмотр 2017 г. } \\
\cline { 2 - 6 } & $\begin{array}{c}2000-2005 \\
\text { (оценка) }\end{array}$ & $\begin{array}{c}2010-2015 \\
\text { (прогно3) }\end{array}$ & $\begin{array}{c}2045-2050 \\
\text { (прогно3) }\end{array}$ & $\begin{array}{c}2010-2015 \\
\text { (оценка) }\end{array}$ & $\begin{array}{c}2045-2050 \\
\text { (прогно3) }\end{array}$ \\
\hline Ангола & 6,75 & 6,04 & 2,98 & 5,95 & 3,80 \\
Нигер & 7,45 & 6,88 & 3,78 & 7,40 & 4,79 \\
Нигерия & 5,85 & 4,74 & 2,40 & 5,74 & 3,55 \\
\hline
\end{tabular}

Источники: [WРP 2006, 2017].

Как следует из прогноза, подготовленного в 2006 г., значения КСР на 2010-2015 гг. в двух из трех стран оказались существенно ниже, чем уточненные статистические оценки, рассчитанные позже, а новый прогноз на середину столетия во всех трех странах существенно превосходит прогноз 2006 г. Особенно выделяется Нигерия, где прогноз и оценка на 2010-2915 гг. различаются на 1 ребенка (на одну женщину)! Поскольку прогнозные значения в середине века по последнему прогнозу более чем на 1 ребенка выше, чем в пересмотре 2006 г., значительное превышение КСР в первой половине XXI века приводит к существенной разнице в численности населения страны к середине века: 410,6 млн человек по последнему прогнозу по сравнению с 288,7 млн по прогнозу 2006 г., т.е. разница составила более 120 млн человек! Существенное влияние заложенных при расчетах прогнозных значений суммарной рождаемости на примере только одной страны (Нигерии) подтверждается также при сравнении прогнозов численности населения страны в «соседних» пересмотрах 2010 и 2012 г., выполненном Мадсеном ${ }^{3}$ Более детальному обоснованию причин существенных расхождений между указанными пересмотрами Отдел народонаселения ООН посвятил специальный выпуск бюллетеня Population Facts в декабре 2013 г. [PopFacts 2013]. В этом выпуске показано, что наибольший вклад (600 млн человек к 2100 г.) в разницу между двумя пересмотрами внесен после корректировки прогноза рождаемости по африканским странам, вызванной учтенными в прогнозе 2012 г. свежими данными обследований населения, проведенных в 2010-2011 гг.

\section{КАК ОЦЕНИТЬ КАЧЕСТВО ДЕМОГРАФИЧЕСКИХ ПРОГНОЗОВ?}

Есть несколько подходов к решению проблемы оценки качества прогноза, для чего

\footnotetext{
${ }^{3}$ Madsen E. (2013). New UN population projections released: pockets of high fertility drive overall increase // NewSecurityBeat - the blog of the Environmental Change and Security Program. June 26. URL: https://www.newsecuritybeat.org/2013/06/population-projections-released-pockets-high-fertility-drive-increase/ (дата обращения: 25.09.2017).
} 
используются различные термины: точность (accuracy), надежность (reliability), неопределенность (uncertainty) прогноза. Категории источников ошибок в прогнозе, согласно Хану и Лутцу [Khan, Lutz 2007]:

- ошибки в исходных данных (неполнота, трудности учета, искажения, недоучет при проведении переписей населения);

- неточности в определении прогнозных значений демографических параметров (например, ожидаемой продолжительности жизни при рождении);

- непредсказуемые события (эпидемии, войны, природные катастрофы, такие как наводнения или голод, экономические кризисы, наплыв мигрантов и др.);

- вероятностный характер демографических процессов, приводящий к флуктуациям в оценках чисел родившихся, умерших и мигрантов;

- неточности при формировании моделей для прогнозирования каждой из трех компонент: рождаемости, смертности или миграции, которые могут привести к ошибкам в прогнозных показателях.

При решении вопроса о возможности практического использования демографических прогнозов необходимо различать как минимум две стороны: собственно демографический и внедемографический аспекты.

\section{КАК МОЖНО ОЦЕНИТЬ СОВРЕМЕННЫЕ ПРОГНОЗЫ ООН С ДЕМОГРАФИЧЕСКОЙ ТОЧКИ ЗРЕНИЯ?}

Если коротко, то это демографическая безупречность. Что под этим понимается?

- В максимальной степени используются все доступные сведения национальной демографической статистики и переписей населения, что находит свое подтверждение в разделе источников данных для прогнозов ООН. В случае отсутствия или низкого качества этой статистики используются результаты выборочных обследований населения.

- Учитываются как общемировые закономерности и тенденции, так и исторические тренды основных демографических характеристик на уровне отдельных стран и регионов (рождаемости, смертности и миграции).

- Устранены факторы субъективности экспертных оценок, влияние роли числа экспертов, а также нормативный подход в определении будущей эволюции прогнозных параметров, которая рассчитывается с использованием многопараметрических моделей.

- Взгляды представителей мировой демографической науки на анализ демографических тенденций, их теоретическое объяснение и понимание в максимально возможной степени используются при прогнозировании. Это, например, концепция демографического перехода, модельные таблицы смертности и др.

- Технология построения прогноза позволяет проверять различные сценарии перспективной демографической динамики, тестировать прогнозы для отдельных стран и территорий, производить их настройку и увязку, обеспечить согласованность 
различных показателей, привлекать к разработке прогноза специалистов из разных стран.

Однако достаточно ли перечисленных достоинств для гарантии расчета действительно надежного прогноза? Для ответа на этот вопрос необходимо понять, что система прогнозирования учитывает явным образом, а что не учитывает вовсе. При внимательном рассмотрении оказывается, что в моделях, применяемых для оценки предстоящей эволюции демографических характеристик, в качестве фактора явно используется ТОЛЬКО время $\mathrm{t}$ ! Необходимо заметить, конечно, что, строго говоря, это не просто календарный период на горизонте прогноза, а относительное время текущей стадии демографического перехода для каждой конкретной страны. Однако при этом за бортом прогноза оказываются огромные пласты различного уровня факторов, которые в принципе могут существенно повлиять на течение демографического перехода. Они включают в себя следующие группы:

- экономическое развитие как важный фактор демографического поведения;

- климатические и экологические факторы, которые могут влиять на здоровье и смертность;

- изменения в социальной и политической организации общества во многих странах мира;

- рост или сохранение гетерогенности населения и неравенства различных регионов, слоев и групп: этнических, социальных, конфессиональных и др.;

- непредсказуемость демографической политики на национальном уровне.

Каждая из этих групп факторов в свою очередь содержит немало аспектов, компонентов или подсистем. Проиллюстрируем это на примере гетерогенности (неоднородности) населения по широкому набору признаков. В их качестве могут быть приведены следующие:

- уровень доходов и их источники;

- условия проживания и уровень жизни;

- ассортимент пищевых продуктов, меню, регулярность и объем питания;

- стиль жизни, физические нагрузки, стрессы, гиподинамия;

- объем, качество и доступность питьевой воды;

- риски природных и техногенных катастроф;

- угрозы терактов, военных, межэтнических, религиозных конфликтов;

- региональная дифференциация уровня и темпов урбанизации, автомобилизации;

- д доступность и оперативность служб спасения, качество врачебной помощи;

- подверженность действию излучений, химических веществ, медикаментов.

В свою очередь данный список как, очевидно, не окончательный может быть легко дополнен еще десятками факторов. По большинству из перечисленных факторов могут серьезно различаться не только страны и регионы мира, но и районы, отдельные населенные пункты и типы поселений внутри каждой страны. 
Что же служит причиной того, что демографические прогнозы тем не менее в основном успешно выполняются? Может быть предложено следующее достаточно общее объяснение:

- население и его поведение очень инерционны, особенно в сравнении с колебаниями экономической конъюнктуры, погодными катаклизмами и социально-политическими пертурбациями;

- действие большинства факторов на демографическое развитие выборочно, локально, а результат может проявиться с большим запаздыванием или только в результате длительного накопления результатов воздействия;

- разнообразные факторы воздействуют на отдельные процессы в населении в общем случае разнонаправлено, а их демографическая результирующая появляется только после агрегирования в один большой пул;

- равнодействующая множества разнонаправленных факторов в целом характеризует прогресс человеческой цивилизации, и она направлена, несомненно, в положительном направлении.

\section{КАКОВА СТЕПЕНЬ ПРИМЕНИМОСТИ ДЕМОГРАФИЧЕСКИХ ПРОГНОЗОВ?}

Отметим еще раз, что прогноз содержит миллионы значений различных показателей, цена ошибки каждого из них, несомненно, различна. С научной точки зрения, ответ на вопрос о том, можно ли использовать прогнозные показатели в решении практических задач, должен решаться на основании детального анализа ошибок, которые содержались в предыдущих прогнозах. В качестве образца фундаментального исследования в этой области могла бы быть взята сделанная в конце прошлого века работа Нико Кельмана [Kelman 1997]. Однако возможно ли и целесообразно ли повторение подобного исследования? Ответ, видимо, не будет положительным по следующим двум основным причинам.

1) Новейшие прогнозы ООН последних пересмотров 2010-2017 гг. [WPP 2010, 2012, 2015a, 2017] существенно отличаются по используемой методике от сделанных ранее. То есть четыре последних прогноза в отличие от прогнозов 2008 г. и предыдущих представляют собой, по сути, совершенно разные прогнозы. Поэтому любые апостериорные оценки ошибок, сделанных, например, в пересмотрах 1998 или 2006 г., дадут слишком мало информации о возможных ошибках в новейших прогнозах. С другой стороны, прогнозы пересмотров 2010-2017 гг. имеют слишком короткую историю (7 лет), чтобы получить такие апостериорные оценки сделанных в них ошибок для горизонта выполненного прогноза хотя бы в 20-30 лет.

2) Вероятностное прогнозирование, примененное в новейших пересмотрах, дает достаточное представление о степени их точности и риске ошибки. Поэтому содержащиеся доверительные интервалы основных показателей позволяют исследователям, работающим с прогнозом, оценить величину возможных ошибок и принять решение о целесообразности использования прогнозного значения конкретного демографического индикатора. В этом решении невозможно обойтись без анализа двух важнейших измерений: временного горизонта прогнозирования и территориального уровня. 


\section{КРАТКОСРОЧНЫЕ ПРОГНОЗЫ}

Длина периода, на который делается прогноз, обычно используется для градации прогнозов как краткосрочных (10-20 лет), среднесрочных (20-40 лет) и долгосрочных (более 40 лет). Что касается краткосрочных прогнозов, в том числе ООН, представляется, что они могут рассматриваться как достаточно точные, обоснованные и пригодные для использования в практических целях экономического или экологического прогнозирования и в других сферах.

В этом случае, например, представляются вызывающими доверие оценки рейтинга наиболее крупных стран мира в не столь отдаленном будущем - в 2030 г. Как показано в таблице 4, рейтинги стран по последним двум пересмотрам совпадают, при этом прогнозная численность различается не более чем на $1-2 \%$.

Таблица 4. Рейтинг первой десятки стран по численности населения в 2030 г., млн человек, прогнозы ООН пересмотра 2015 и 2017 гг.

\begin{tabular}{c|l|r|r}
\hline \multirow{2}{*}{ № п/п } & \multirow{2}{*}{ Страна } & \multicolumn{2}{|c}{ Год пересмотра } \\
\cline { 3 - 4 } & & 2015 & 2017 \\
\hline 1 & Индия & 1528 & 1513 \\
2 & Китай & 1416 & 1441 \\
3 & США & 356 & 354 \\
4 & Индонезия & 295 & 295 \\
5 & Нигерия & 263 & 264 \\
6 & Пакистан & 245 & 244 \\
7 & Бразилия & 229 & 225 \\
8 & Бангладеш & 186 & 186 \\
9 & Мексика & 148 & 148 \\
10 & Россия & 139 & 141 \\
\hline
\end{tabular}

Источники: [WPP 2015a, 2017].

Приведем примеры практических задач, где возможно использование краткосрочного прогноза: оценка требуемого количества доз вакцин и прививок в данной стране, числа учеников школьного возраста, объема потребности в питьевой воде, числа жителей страны в пенсионном возрасте, плотности населения и др.

С увеличением прогнозного горизонта растет и степень неопределенности будущего. Это, конечно, достаточно универсальный принцип, и он имеет место даже для сравнительно небольших стран с прекрасной статистикой населения и ее длительной историей, например для Норвегии, где данная проблема была отмечена в последних прогнозах населения страны [Tønnessen et al. 2016]. И там, и в прогнозах ООН растущая неопределенность будущего проявляется в том, что коридор доверительного интервала расширяется с переходом к более отдаленному периоду. Среднесрочные прогнозы представляются уже менее точными, поскольку возникает угроза того, что накопленная результирующая сила воздействия какого-либо неучтенного фактора при длительном воздействии может достаточно серьезно поколебать оценки предстоящего будущего. Но это вовсе не означает, что их нельзя применять. Скорее, наоборот. Для ряда задач применение результатов прогноза может оказаться необходимым и полезным. Рассмотрим пример эколога, который оценивает ожидаемый уровень выбросов $\mathrm{CO}_{2}$ в Индии к 2040 г. По прогнозу ООН, население страны к этому сроку составит 1,6 млрд человек и с 
вероятностью 95\% оно будет находиться в интервале 1,5-1,7 млрд. В принципе, любое число в указанном диапазоне эколог может взять в качестве значения фактора, определяющего уровень этих выбросов, поскольку риск ошибки окажется, скорее всего, значительно ниже, чем риски, связанные с другими, не менее важными компонентами, определяющими этот уровень, такими как уровень экономического развития, степень автомобилизации или развитие атомной энергетики. Для перечисленных факторов вряд ли ему удастся использовать более точные прогнозы этих и других компонент по сравнению с демографическими (возможное отклонение всего $\pm 7 \%$ ).

\section{КАКИЕ СУЩЕСТВУЮТ ДРУГИЕ ПРОГНОЗЫ МИРОВОГО НАСЕЛЕНИЯ?}

Оценивая прогноз ООН, необходимо, конечно, иметь в виду, что есть и другие, альтернативные сценарии и прогнозы мирового населения. Наряду с ОOН, опыт построения множества различных прогнозов населения мира и отдельных стран имеют другие международные научные организации и национальные статистические ведомства: Бюро цензов США (US Census Bureau), Международный институт прикладного системного анализа (IIASA), Бюро данных о народонаселении (Population Reference Bureau), Венский институт демографии (Vienna Institute of Demography), Мировой банк (World Bank) и др. В отличие от «чисто демографических» прогнозов представляет интерес, например, доклад Римскому Клубу, подготовленный Рандерсом Йоргеном, содержащий прогнозы перспективного состояния не только населения, но и климата, экономики, социальных и других процессов в 2052 г. В этих прогнозах, в частности, принят во внимание фактор, который может поколебать традиционные прогнозные оценки не только количественно, но и качественно, - уровень урбанизации. В представленном докладе приведена своя оценка максимальной численности мирового населения к 2040 г. на уровне 8,1 млрд человек, после чего ожидается ее снижение [Jorgen 2012].

\section{КАК МОГУТ БЫТЬ ОЦЕНЕНЫ ДОЛГОСРОЧНЫЕ ДЕМОГРАФИЧЕСКИЕ ПРОГНОЗЫ?}

Обсудим вопрос о долгосрочном прогнозе с временным горизонтом, превышающим 50 лет. То, что на численность и состав населения в столь отдаленной перспективе может повлиять множество различных факторов, большинство из которых прогнозировать крайне затруднительно, представляется несомненным. Рассмотрим более детально следующие три группы этих факторов. Первая группа - факторы, которые всегда существовали ранее, однако они носят во многом случайный характер и трудно прогнозируемы принципиально: землетрясения, цунами, наводнения, экономические кризисы и техногенные катастрофы. Еще одна группа - факторы, действующие наперекор процессам глобализации и общемировым тенденциям взаимной конвергенции. Они включают в себя новые характеристики политического, социального и экономического развития, а также перераспределения населения по территориям, которые в совокупности порождают все новые проблемы, неоднородности, неравномерности и угрозы. К ним можно отнести, например, растущую плотность населения, дефицит питьевой воды, неравенство населения 
разных стран перед угрозами военных и межэтнических конфликтов. В третью группу можно включить принципиально новые угрозы, которые могут существенно повлиять на будущее развитие демографических процессов, однако, предугадать, сколько их и какие именно угрозы могут возникнуть, еще труднее. Для обоснования высоких шансов возникновения таких проблем в отдаленном будущем вернемся на время к середине ХX века. Если бы в то время решалась задача построения прогнозов населения в современном их понимании, вряд ли можно было бы предсказать и тем более количественно учесть такие факторы, как появившаяся позднее эпидемия СПИДа, распространение генномодифицированных продуктов, вспомогательные репродуктивные технологии, изменение климата, радиоактивные и электромагнитные излучения... Что же говорить о Чернобыле или Фукусиме?

Приведенные три группы процессов в природе и обществе, которые в будущем могут существенно повлиять на здоровье населения и развитие демографических процессов и предсказание которых крайне затруднительно, неизбежно приводят к заключению, что к долговременному прогнозу необходимо подходить с высокой степенью скептицизма и давать себе отчет в его условности. Не доверять прогнозным показателям нам не позволяют не столько неточности в исходных данных или погрешности в собственно демографических расчетах, сколько то, что прогнозируемые показатели и структуры в значительной степени зависят от процессов, происходящих вне собственно демографии. Но демографы вовсе не претендуют на то, что они являются одновременно также и экономистами, экологами, политиками, психологами или фантастами-футурологами, которым ясны все факторы, способные в будущем формировать демографическое поведение. А вот решение вопроса, применять или не применять демографический прогноз в столь отдаленной перспективе, несомненно, зависит от того, какая конкретная прикладная задача решается. Здесь важно отметить, что новейшие прогнозы ООН дают меру риска того, что этот прогноз может не сбыться. Например, по вероятностному прогнозу ООН, население Нигерии к 2080 г. составит от 350 до 1000 млн человек. Риск того, что оно будет вне указанного интервала, составит 0,05. Если экономиста-футуролога такое соотношение риска ошибки и величины интервала устраивает, он сможет воспользоваться прогнозом для расчетов других необходимых ему социально-экономических индикаторов. Но ценность использования информации о перспективной численности населения из столь широкого интервала представляется крайне невысокой.

\section{ЧТО НЕОБХОДИМО УЧЕСТЬ ПРИ ИСПОЛЬЗОВАНИИ ПРОГНОЗА НЕ НА УРОВНЕ МИРА В ЦЕЛОМ, А ДЛЯ ОТДЕЛЬНЫХ ТЕРРИТОРИЙ?}

Другой важнейший аспект оценки демографического прогноза - территориальный уровень. Степень точности и достоверности прогнозов по большинству стран и регионов мира в краткосрочной и среднесрочной перспективе можно оценить достаточно высоко. Как показывает опыт предыдущих прогнозов, относительная ошибка в оценках численности населения в них, скорее всего, не будет превышать 3-5\%. В качестве примера можно привести Францию, население которой к 2030 г. по среднему варианту прогноза составит 67,9 млн человек, а «вилка» при доверительном интервале 95\% оценивается от 66 до 69 млн 
[WPP 2017]. Другими словами, риск того, что численность населения окажется вне этого небольшого $\pm 2 \%$-ого интервала, составит 0,05 . Однако это справедливо, к сожалению, не для всех стран. К числу «сомнительных» необходимо отнести, прежде всего, некоторые развивающиеся страны, где до сих пор отсутствует система учета естественного движения населения или качество этого учета оставляет желать лучшего. В прогнозных расчетах для них ошибка может превысить 10\% или даже 15\%. Например, в Афганистане число детей в возрасте до 15 лет к 2030 г. по среднему варианту прогноза составит 16,45 млн. Но ширина доверительного интервала превысит $\pm 20 \%$ [WPP 2017]! Нельзя исключить также, что и в XXI веке в некоторых странах могут произойти значительные крутые «повороты» в демографическом развитии, вызванные различными причинами. Для иллюстрации могут служить три примера. Первый - это Китай, где политика «Одна семья - один ребенок» привела к существенному сокращению рождаемости. Достаточно ярко этот результат заметен, если сравнить эволюцию коэффициента суммарной рождаемости в Китае с Индией, где она происходила «естественным путем», т.е. без кардинального вмешательства государства. Как проиллюстрировано на рисунке 3, в Китае в течение 30 лет КСР был в среднем на 1 ребенка ниже, чем в Индии, если за отправную точку взять примерно равные начальные его уровни (для этого показатели по Индии необходимо сдвинуть на 10 лет). Результат такой политики в Китае можно оценить с помощью условного «ретроспективного» демографического прогноза населения, если бы он делался в 1970 г., где в «мягком» варианте предстоящей динамики рождаемости была бы взята рождаемость Индии. В этом случае прогнозная оценка численности населения Китая к 2005 г. оказалась бы на 400 млн человек больше, чем это оказалось в действительности! Очередной крутой поворот для Китая после отмены указанной жесткой политики может еще раз ожидать нас в ближайшие десятилетия.

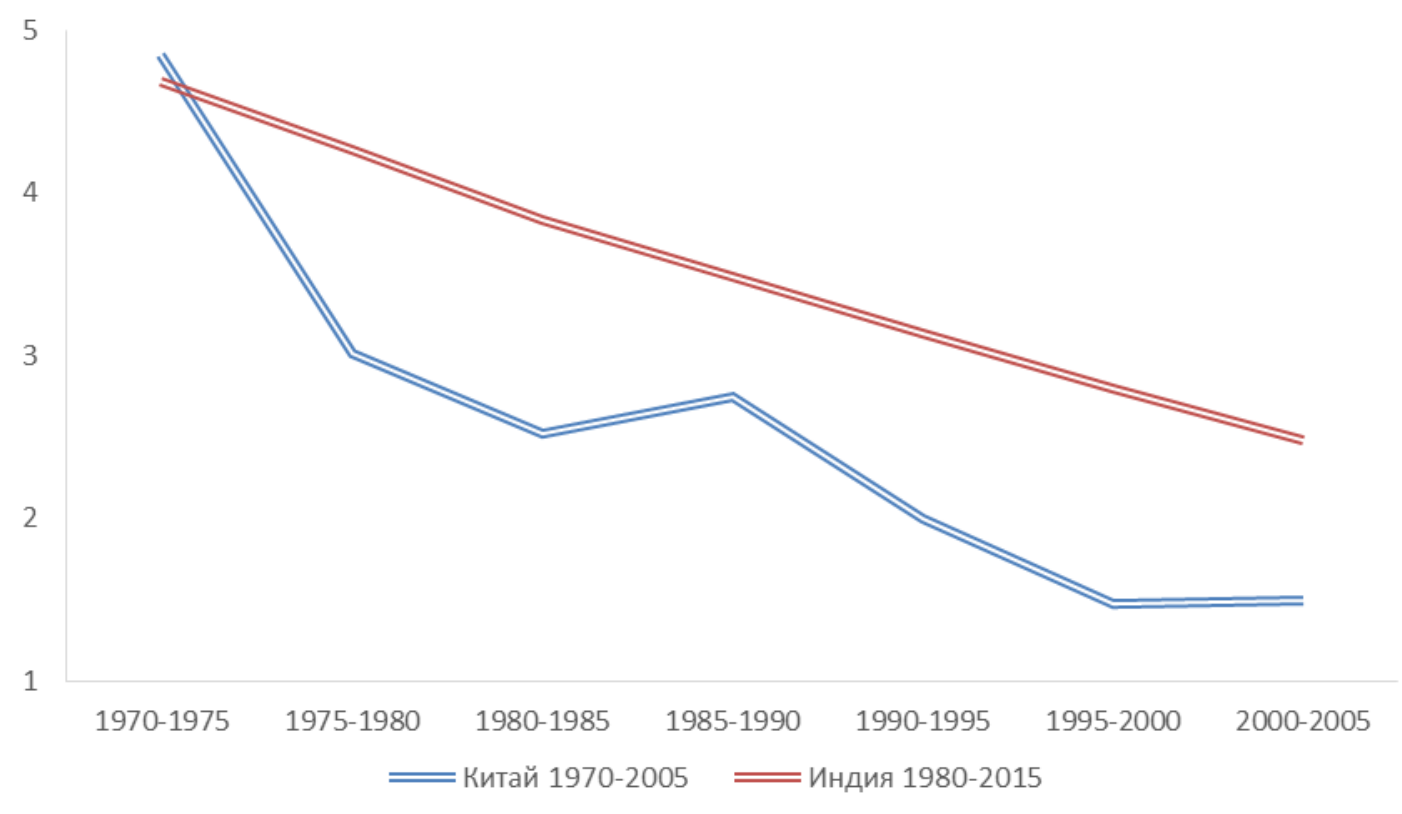

\section{Рисунок 3. Коэффициент суммарной рождаемости в Китае (1970-2005 гг.) и Индии (1980-2015 гг.), детей на 1 женщину}

Примечание. Линия для Индии сдвинута на 10 лет для совмещения начального уровня. 
Источник: [WPP 2015a].

Еще один очень интересный пример 2 - Иран. Динамика КСР в Иране и восьми других странах ближайшего региона за последние 40 лет представлена на рисунке 4.

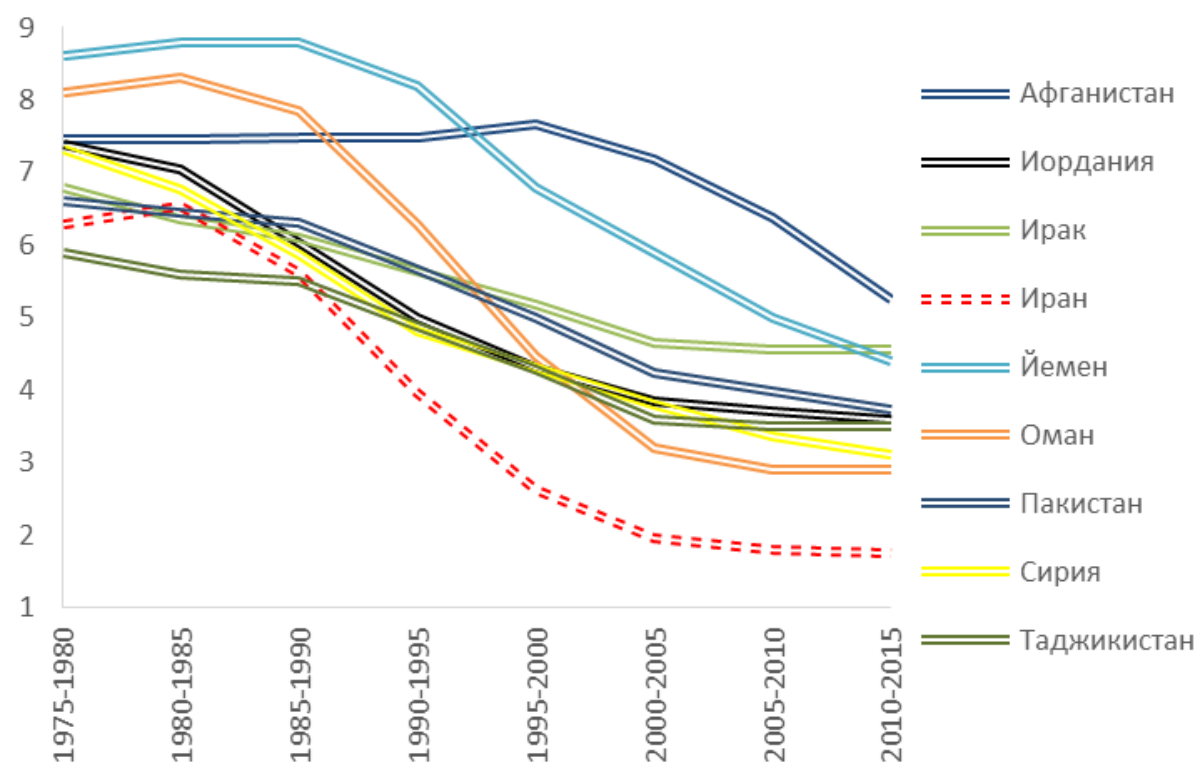

Рисунок 4. Коэффициент суммарной рождаемости в Иране и некоторых соседних странах, 1975-2015

Источник: [WPP 2015a].

График на рисунке 4 демонстрирует демографически достаточно уникальную историческую эволюцию рождаемости в отдельной стране, когда в течение 20 лет после исламской революции она сократилась более чем втрое. При этом, в отличие от Китая, снижение произошло без жесткой государственной антинаталистской политики.

Для этого примера можно предугадать потенциальную демографическую «осечку», если бы демографический прогноз для Ирана готовился в 1980 г. Вряд ли мог бы найтись в мире такой демограф, который осмелился бы тогда утверждать, что через 20 лет КСР окажется там ниже 2 детей на женщину.

И, наконец, нельзя не упомянуть пример 3 - Россию. Активная демографическая политика последних лет не только продемонстрировала свою результативность, но и нашла достаточно яркое отражение в эволюции прогнозов ООН. Для иллюстрации рассмотрим примеры последних пяти пересмотров (таблица 5).

Таблица 5. Прогноз численности населения России на 2025, 2050 г. по прогнозам ООН пересмотров 2006, 2008, 2012, 2015 и 2017 г., тыс. человек

\begin{tabular}{l|c|c|c|c|c}
\hline \multirow{2}{*}{ Прогнозный период } & \multicolumn{5}{|c}{ Год пересмотра } \\
\cline { 2 - 6 } & 2006 & 2008 & 2012 & 2015 & 2017 \\
\hline 2025 г. & 128193 & 132345 & 136967 & 141205 & 142607 \\
2050 г. & 107832 & 116097 & 120896 & 128599 & 132731 \\
\hline
\end{tabular}

Источники: [WPP 2006, 2008, 2012, 2015a, 2017]. 
Таким образом, за исторически короткий период всего лишь в 11 лет прогнозные оценки $\mathrm{OOH}$, сделанные для населения России, к середине века выросли почти на 25 млн человек!

Приведенные три примера дают основание утверждать, что, несмотря на демографическую безупречность, прогнозы ООН подвержены риску не оправдаться для некоторых стран по причинам, которые должны быть отнесены к категории не чисто демографических. По большинству показателей и стран прогноз может быть использован в практических целях, например, в социально-экономическом прогнозировании, но при этом следует проявлять определенную осторожность и скептицизм и делать по этому поводу оговорки об условности демографического прогноза. Нельзя исключить появление некоторых стран, для которых понятие «прогноз» становится не совсем корректным и уместным. Причина - в невозможности не только правильно спрогнозировать численность населения, но и вообще предугадать, предвидеть, что предстоящие изменения могут оказаться столь значительными, а направление этих изменений - столь неожиданным. Для таких стран вопрос не столько в некоторой количественной погрешности, а в качественно принципиальном фиаско при применении любого традиционного прогнозирования. Например, нельзя исключить возможность того, что Нигерия в ближайшие полстолетия пойдет по пути Китая или Ирана, что может опрокинуть сделанные для нее до сих пор прогнозные оценки.

\section{А ВСЕ ЛИ ТАК ПЛОХО?}

По прогнозам ООН, общий тренд роста мирового населения вплоть до конца века сохранится. Но возникает вопрос, а действительно ли эти перспективы столь неблагоприятны, чтобы оправдать алармистское восприятие этого прогноза? Чтобы убедиться в том, что ожидаемое будущее не столь безнадежно, рассмотрим вначале такой показатель, как темпы абсолютного прироста населения в течение оставшейся части XXI века.

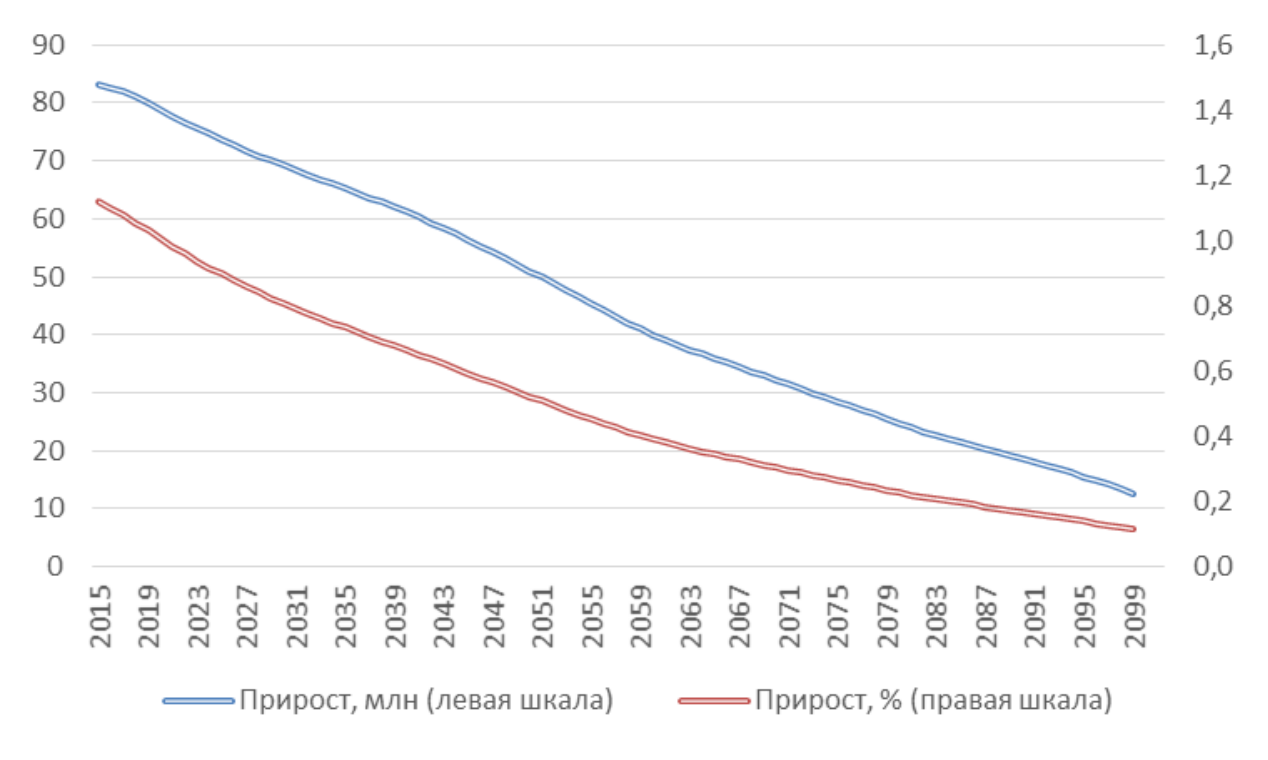




\section{Рисунок 5. Ежегодный прирост мирового населения согласно среднему варианту прогноза ООН пересмотра 2015 г., 2015-2100, абсолютный в млн человек, относительный в \%}

Источник: [WPP 2015a].

Как показано на рисунке 5, за 85 лет прирост мирового населения сократится в 6,5 раза. Однако несколько больший оптимизм вызывает динамика относительного прироста, снижение этого показателя к концу века будет десятикратным! А это позволяет достаточно уверенно сделать заключение, что наступление эпохи стабилизации и снижения численности населения Земли не отменяется совсем, а лишь откладывается, и появляются некоторые надежды ее наступления несколько позже - в начале XXII века.

\section{ЕСТЬ ЛИ У ПРОГНОЗА ООН СЛАБЫЕ СТОРОНЫ?}

Наряду с достаточно устойчивой в целом тенденцией неуклонного совершенствования прогнозов ООН от пересмотра к пересмотру, а также отмеченной выше их демографической безупречностью, это вовсе не означает, что история этих прогнозов абсолютно безоблачна, они вовсе лишены недостатков и не вызывают никаких нареканий. Поэтому для читателя может представлять определенный интерес перечисление некоторых замечаний. К примеру, у многих демографов в свое время множество вопросов вызвал пересмотр 2004 г., где проявилась явная «уравниловка» совершенно разных стран мира, притом не только развитых и имеющих рождаемость на уровне ниже простого воспроизводства населения, для которых к середине XXI века она ожидалась в среднем варианте прогноза на уровне 1,85 ребенка на 1 женщину. Изумление вызвало не само значение показателя и не совпадение этой величины в странах с разными трендами рождаемости, а число этих стран, которых в этом пересмотре оказалось более сотни! Здесь, очевидно, планка стремления экспертов к «всеобщему» консенсусу по поводу этого прогнозного уровня для совершенно различных стран была явно завышена. Необходимо отметить также, что Отдел народонаселения UN DESA неоправданно нерачительно обращается с результатами своего труда, что проявляется в том, что после публикации результатов очередного пересмотра основной массив файлов и интернет-страниц предыдущего прогноза становится недоступным. Небольшим исключением являются лишь публикации, содержащие описание основных результатов прогноза, но они почему-то постоянно меняют свои названия: Highlights (2004), Analytical Report (2006), Highlights and Advance Tables (2012), Key Findings and Advance Tables (2015) и др. [WPР 2004, 2006, 2012, 2015a]. Интернет-страницы, опубликованные для пересмотра 2015 г., после выхода результатов следующего пересмотра исчезают, а ссылки на эти публикации в многочисленных публикациях теряют смысл. В отличие от демографических ежегодников $\mathrm{OOH,} \mathrm{полный} \mathrm{комплект} \mathrm{которых} \mathrm{с} 1948$ г. доступен через Систему демографических ежегодников [DYS 2018], некоторые пересмотры на сайте прогноза ООН [WPP 2017] вообще отсутствуют и доступны лишь на других, внешних по отношению к ООН сайтах. Еще один недостаток - отсутствие основных документов прогноза на одном из официальных языков ООН - русском, перевод на который по стоимости вряд ли превышает 0,1-0,2\% от всех работ по прогнозированию и уже оплачен взносами в ООН стран с 
русскоговорящим населением (это не только Россия, но и Белоруссия, Украина, Казахстан и др.). Еще одна заметка по поводу публикации основных результатов прогноза относится к немалому числу различных версий «окончательных» (final) или «исправленных» (revised) их версий, многие из которых были опубликованы лишь через 1-2 или даже 4 года после выполнения прогноза соответствующего пересмотра. По этой причине, чтобы избежать путаницы между годом пересмотра и годом выхода соответствующих документов, в списке литературы в настоящей статье для них указан год пересмотра, а не год издания. Некоторые неточности были также замечены в описании источников данных, например, в пересмотре 2015 г. для сведений по смертности для населения России указывался в качестве источника Human Mortality Database для периода, который на самом деле в этой базе данных не был представлен в полном объеме. В последнем пересмотре небрежно оформлена легенда для оценок 1950-2015 гг., названных «observed», в разделе «Графики» для численности населения; их в ней найти крайне затруднительно (линия из тире с жирной точкой на графике описана в легенде как сплошная синяя).

\section{ЗАКЛЮЧЕНИЕ}

Рассмотренный в статье прогноз населения мира, выполненный ООН в 2017 г., представляет собой результат серьезной и глубокой работы с представлением подробной разносторонней информации о предстоящем демографическом будущем. Прогноз может рассматриваться как серьезное достижение современной статистики, компьютерного моделирования и науки о народонаселении. Несмотря на то, что многие рассмотренные в статье факторы и причины, лежащие вне собственно демографических процессов, оказались непосредственно неучтенными в этом прогнозе, достоверность и обоснованность основных выводов и тенденций необходимо оценить достаточно высоко, а результаты прогноза могут быть использованы широкими кругами специалистов различного профиля: экономистами, политиками, экологами, социологами и представителями многих других областей. В краткосрочной перспективе точность этого прогноза может быть оценена на высоком уровне. Что же касается более отдаленной перспективы, прогнозные показатели могут быть также рекомендованы, но лишь в качестве ориентиров, прежде всего просто за неимением пока более глубоких системных междисциплинарных исследований и методик прогнозирования. При этом, однако, они должны восприниматься с некоторым скептицизмом и использоваться с осторожностью и с учетом результатов вероятностных характеристик прогнозируемых индикаторов. Пользователям прогноза необходимо отдавать себе отчет в определенной их условности и риске возможных погрешностей некоторых показателей для ряда стран и регионов мира, связанных с высокой степенью неопределенности будущего.

\section{ЛИТЕРАТУРА}

DYS (2018). United Nations. Department of Economic and Social Affairs. Statistics Division. Demographic Yearbook System. 1948-2016. URL: https://unstats.un.org/unsd/demographicsocial/products/dyb/\#statistics (дата обращения: 21.05.2018). 
Gerland P., A.E. Raftery, H. Ševčíková, N. Li, D. Gu, T. Spoorenberg, L. Alkema, B.K. Fosdick, J. Chunn, N. Lalic, G. Bay, T. Buettner, G.K. Heilig, J. Wilmoth (2014). World population stabilization unlikely this century // Science. 10 (October). Vol. 346. Is. 6206: 234-237.

Jorgen R. (2012). 2052: A global forecast for the next forty years. Vermont, USA: Chelsea Green Publishing. 304 p.

Keilman N. (1997). The Accuracy of the United Nation's World Population Projections // Statistics Norway. Documents. 97/4 (March). URL: https://www.ssb.no/a/histstat/doc/doc_199704.pdf (дата обращения: 18.05.2018).

Khan H.T.A., W. Lutz (2007). How well did past UN Population Projections anticipate demographic trends in six Southeast Asian countries? // Oxford Institute of Ageing. Working paper 507. Oxford, UK. URL: http://www.ageing.ox.ac.uk/files/workingpaper_507.pdf (дата обращения: 08.07.2017).

Kunzig R. (2014). A world with 11 billion people? New Population projections shatter earlier estimates // National Geographic. URL:

http://news.nationalgeographic.com/news/2014/09/140918-population-global-united-nations2100-boom-africa/ (дата обращения: 08.07.2017).

Lutz W., W. Sanderson, S. Scherbov (1997). Doubling of world population unlikely // Nature. Vol. 387: 803-805.

PopFacts (2013). Explaining differences in the projected populations between the 2012 and 2010 Revisions of World Population Prospects: The role of fertility in Africa // Population Facts. UN DESA PD. 10. URL:

http://www.un.org/en/development/desa/population/publications/pdf/popfacts/PopFacts_201 3-10_new.pdf (дата обращения: 26.03.2018).

Population projections. Don't panic (2014). A UN study sparks fears of a population explosion. The alarm is misplaced // The Economist. URL: https://www.economist.com/news/international/21619986-un-study-sparks-fears-populationexplosion-alarm-misplaced-dont-panic (дата обращения: 08.07.2017).

Sevcikova H., A.E. Raftery, P. Gerland (2013). Bayesian probabilistic population projections: do it yourself // United Nations Statistical Commission and Economic Commission for Europe Statistical Office of the European Union (Eurostat). Joint Eurostat/UNECE Work Session on Demographic Projections organised in cooperation with Istat (29-31 October 2013, Rome, Italy). Item 13 - Bayesian approaches. WP 13.2. URL:

https://www.unece.org/fileadmin/DAM/stats/documents/ece/ces/ge.11/2013/WP_13.2.pdf (дата обращения: 23.05.2018).

Tønnessen M., S. Leknes, A. Syse (2016). Population projections 2016-2100: main results // Statistics Norway. URL: https://www.ssb.no/en/befolkning/artikler-ogpublikasjoner/_attachment/270675?_ts=15571cbb700 (дата обращения: 21.05.2018).

Wilmoth J. (2015). Global population projections by the United Nations // Joint Statistical Meetings. Session 151 "Better demographic forecasts, better policy decisions". Seattle, 10 August. Presentation. URL:

http://www.un.org/en/development/desa/population/about/director/pdf/2015.08.10_JSM_slid es.pdf (дата обращения: 08.07.2017).

Worstall T. (2017). The problematic assumption in the UN's 9.8 Billion people projection // Forbes. June. URL: https://www.forbes.com/sites/timworstall/2017/06/22/the-problematicassumption-in-the-uns-9-8-billion-people-projection/\#b499e6d32918 (дата обращения: 25.09.2017). 
WP (2004). United Nations. Department of Economic and Social Affairs. Population Division. World Population to 2300. New York: United Nations. URL:

http://www.un.org/esa/population/publications/longrange2/WorldPop2300final.pdf (дата обращения: 18.05.2018).

WPP (1998). United Nations. Department of Economic and Social Affairs. Population Division. World Population Projections to 2150. New York: United Nations.

WPP (2004). United Nations. Department of Economic and Social Affairs. Population Division.

World Population Prospects. The 2004 Revision. Highlights. New York: United Nations.

URL:

http://www.un.org/esa/population/publications/WPP2004/2004Highlights_finalrevised.pdf (дата обращения: 18.05.2018).

WPP (2006). United Nations. Department of Economic and Social Affairs. Population Division.

World Population Prospects. The 2006 Revision. Vol. III: Analytical Report. New York:

United Nations. URL:

http://www.un.org/esa/population/publications/WPP2006RevVol_III/WPP2006RevVol_III_f inal.pdf (дата обращения: 18.05.2018).

WPP (2008). United Nations. Department of Economic and Social Affairs. Population Division.

World Population Prospects. The 2008 Revision. Highlights. New York: United Nations.

URL: http://www.un.org/esa/population/publications/wpp2008/wpp2008_highlights.pdf

(дата обращения: 18.05.2018).

WPP (2010). United Nations. Department of Economic and Social Affairs. Population Division.

World Population Prospects. The 2010 Revision. Vol. I: Comprehensive Tables. New York:

United Nations. URL:

http://www.un.org/en/development/desa/population/publications/pdf/trends/WPP2010/WPP2

010_Volume-I_Comprehensive-Tables.pdf (дата обращения: 18.05.2018).

WPP (2012). United Nations. Department of Economic and Social Affairs. Population Division.

World Population Prospects. The 2012 Revision. Highlights and Advance Tables. New York:

United Nations. URL:

https://esa.un.org/unpd/wpp/publications/Files/WPP2012_HIGHLIGHTS.pdf (дата

обращения: 18.05.2018).

WPP (2015a). United Nations. Department of Economic and Social Affairs. Population Division.

World Population Prospects. The 2015 Revision. Key Findings and Advance Tables. New

York: United Nations. URL:

https://esa.un.org/unpd/wpp/publications/files/key_findings_wpp_2015.pdf (дата

обращения: 18.05.2018).

WPP (2015b). United Nations. Department of Economic and Social Affairs. Population Division.

World Population Prospects. The 2015 Revision, Methodology of the United Nations

Population Estimates and Projections. New York: United Nations. URL:

https://esa.un.org/unpd/wpp/Publications/Files/WPP2015_Methodology.pdf (дата

обращения: (accessed: 18.05.2018).

WPP (2017). United Nations. Department of Economic and Social Affairs. Population Division.

World Population Prospects 2017. URL: https://esa.un.org/unpd/wpp/ (дата обращения:

18.05.2018). 


\title{
ON THE LIMITS OF APPLICATION OF THE UN POPULATION PROJECTIONS
}

\author{
EUGENY SOROKO
}

\begin{abstract}
The last few years have seen a significant growth of interest in UN population projections. The latest such projection made by the UN Population Division was published in 2017, and is, on the whole, in agreement both with previous UN projections and projections conducted by other institutions. According to the 2017 Revision, world population size will reach 9.772 billion persons in 2050 and 11.184 billion in 2100. However, these dry figures themselves cannot explain the appearance of harsh criticism of these projections. This paper aims to get a better grip on the real reason for this criticism - the new methods used in these projections and their significant reworking, or the results themselves. For this purpose, an analysis is made of the recent UN projections, their methods, the data used, and the results of projections made in the last 15 years. Shortcomings of the UN projections are discussed, as well as the limitations and conditionality of their possible use. It is shown that among the possible reasons for an increase in projected world population, the most significant ones include: 1) the overestimate of projected infant and child mortality in previous projections, and 2) the underestimate of the rate of fertility decline in several African countries. It is argued that short-term population projections should be trusted and may be used for practical purposes, while the conditionality of applying long-term projections, for which there are multiple possible unpredictable factors of future demographic development, significantly reduces their precision. For particular countries, a great uncertainty of long-term projection may be caused by a sharp change in population policy or sociopolitical organization. This is illustrated by examples for several countries.
\end{abstract}

Key words: population, countries of the world, population projection, UN, revision, methods of projection, fertility, mortality, long-term projection, probabilistic projection.

EugEny Soroko (esoroko@hse.ru), NATIONAL RESEARCH UNIVERSITy HighER SCHOOL OF Economics, RuSSIA.

THE STUDY WAS IMPLEMENTED UNDER THE BASIC RESEARCH PROGRAM AT THE NATIONAL RESEARCH UNIVERSITY HIGHER SCHOOL OF ECONOMICS (HSE) IN 2017. PROJECT "TENDENCY OF DEMOGRAPHIC DEVELOPMENT OF RUSSIA IN THE CONTEXT OF THE LONG-TERM POPULATION TRENDS".

DATE RECEIVED : MARCH 2018.

\section{REFERENCES}

DYS (2018). United Nations. Department of Economic and Social Affairs. Statistics Division. Demographic Yearbook System. 1948-2016. URL: https://unstats.un.org/unsd/demographicsocial/products/dyb/\#statistics (accessed: 21.05.2018).

Gerland P., A.E. Raftery, H. Ševčíková, N. Li, D. Gu, T. Spoorenberg, L. Alkema, B.K. Fosdick, J. Chunn, N. Lalic, G. Bay, T. Buettner, G.K. Heilig, J. Wilmoth (2014). World population stabilization unlikely this century // Science. 10 (October). Vol. 346. Is. 6206: 234-237.

Jorgen R. (2012). 2052: A global forecast for the next forty years. Vermont, USA: Chelsea Green Publishing. 304 p.

Keilman N. (1997). The Accuracy of the United Nation's World Population Projections // Statistics Norway. Documents. 97/4 (March). URL: https://www.ssb.no/a/histstat/doc/doc_199704.pdf (accessed: 18.05.2018).

Khan H.T.A., W. Lutz (2007). How well did past UN Population Projections anticipate demographic trends in six Southeast Asian countries? // Oxford Institute of Ageing. Working 
paper 507. Oxford, UK. URL: http://www.ageing.ox.ac.uk/files/workingpaper_507.pdf (accessed: 08.07.2017).

Kunzig R. (2014). A world with 11 billion people? New Population projections shatter earlier estimates // National Geographic. URL:

http://news.nationalgeographic.com/news/2014/09/140918-population-global-united-nations2100-boom-africa/ (accessed: 08.07.2017).

Lutz W., W. Sanderson, S. Scherbov (1997). Doubling of world population unlikely // Nature. Vol. 387: 803-805.

PopFacts (2013). Explaining differences in the projected populations between the 2012 and 2010 Revisions of World Population Prospects: The role of fertility in Africa // Population Facts. UN DESA PD. 10. URL:

http://www.un.org/en/development/desa/population/publications/pdf/popfacts/PopFacts_201 3-10_new.pdf (accessed: 26.03.2018).

Population projections. Don't panic (2014). A UN study sparks fears of a population explosion. The alarm is misplaced // The Economist. URL:

https://www.economist.com/news/international/21619986-un-study-sparks-fears-populationexplosion-alarm-misplaced-dont-panic (accessed: 08.07.2017).

Sevcikova H., A.E. Raftery, P. Gerland (2013). Bayesian probabilistic population projections: do it yourself // United Nations Statistical Commission and Economic Commission for Europe Statistical Office of the European Union (Eurostat). Joint Eurostat/UNECE Work Session on Demographic Projections organised in cooperation with Istat (29-31 October 2013, Rome, Italy). Item 13 - Bayesian approaches. WP 13.2. URL:

https://www.unece.org/fileadmin/DAM/stats/documents/ece/ces/ge.11/2013/WP_13.2.pdf (accessed: 23.05.2018).

Tønnessen M., S. Leknes, A. Syse (2016). Population projections 2016-2100: main results // Statistics Norway. URL: https://www.ssb.no/en/befolkning/artikler-ogpublikasjoner/_attachment/270675?_ts=15571cbb700 (accessed: 21.05.2018).

Wilmoth J. (2015). Global population projections by the United Nations // Joint Statistical Meetings. Session 151 "Better demographic forecasts, better policy decisions". Seattle, 10 August. Presentation. URL:

http://www.un.org/en/development/desa/population/about/director/pdf/2015.08.10_JSM_slid es.pdf (accessed 08.07.2017).

Worstall T. (2017). The problematic assumption in the UN's 9.8 Billion people projection // Forbes. June. URL: https://www.forbes.com/sites/timworstall/2017/06/22/the-problematicassumption-in-the-uns-9-8-billion-people-projection/\#b499e6d32918 (accessed: 25.09.2017).

WP (2004). United Nations. Department of Economic and Social Affairs. Population Division. World Population to 2300. New York: United Nations. URL: http://www.un.org/esa/population/publications/longrange2/WorldPop2300final.pdf (accessed: 18.05.2018).

WPP (1998). United Nations. Department of Economic and Social Affairs. Population Division. World Population Projections to 2150. New York: United Nations.

WPP (2004). United Nations. Department of Economic and Social Affairs. Population Division. World Population Prospects. The 2004 Revision. Highlights. New York: United Nations. URL:

http://www.un.org/esa/population/publications/WPP2004/2004Highlights_finalrevised.pdf (accessed: 18.05.2018). 
WPP (2006). United Nations. Department of Economic and Social Affairs. Population Division. World Population Prospects. The 2006 Revision. Vol. III: Analytical Report. New York: United Nations. URL:

http://www.un.org/esa/population/publications/WPP2006RevVol_III/WPP2006RevVol_III_f inal.pdf (accessed: 18.05.2018).

WPP (2008). United Nations. Department of Economic and Social Affairs. Population Division.

World Population Prospects. The 2008 Revision. Highlights. New York: United Nations.

URL: http://www.un.org/esa/population/publications/wpp2008/wpp2008_highlights.pdf

(accessed: 18.05.2018).

WPP (2010). United Nations. Department of Economic and Social Affairs. Population Division.

World Population Prospects. The 2010 Revision. Vol. I: Comprehensive Tables. New York:

United Nations. URL:

http://www.un.org/en/development/desa/population/publications/pdf/trends/WPP2010/WPP2

010_Volume-I_Comprehensive-Tables.pdf (accessed: 18.05.2018).

WPP (2012). United Nations. Department of Economic and Social Affairs. Population Division.

World Population Prospects. The 2012 Revision. Highlights and Advance Tables. New York:

United Nations. URL:

https://esa.un.org/unpd/wpp/publications/Files/WPP2012_HIGHLIGHTS.pdf (accessed: 18.05.2018).

WPP (2015a). United Nations. Department of Economic and Social Affairs. Population Division.

World Population Prospects. The 2015 Revision. Key Findings and Advance Tables. New

York: United Nations. URL:

https://esa.un.org/unpd/wpp/publications/files/key_findings_wpp_2015.pdf (accessed: 18.05.2018).

WPP (2015b). United Nations. Department of Economic and Social Affairs. Population Division.

World Population Prospects. The 2015 Revision, Methodology of the United Nations

Population Estimates and Projections. New York: United Nations. URL:

https://esa.un.org/unpd/wpp/Publications/Files/WPP2015_Methodology.pdf (accessed:

18.05.2018).

WPP (2017). United Nations. Department of Economic and Social Affairs. Population Division.

World Population Prospects 2017. URL: https://esa.un.org/unpd/wpp/ (accessed:

18.05.2018). 